\section{Occurrence and antimicrobial resistance of Campylobacter jejuni isolates from poultry in Casablanca-Settat, Morocco}

\author{
Khadija Es-soucratti, ${ }^{1,2}$ \\ Abderrahman Hammoumi, ${ }^{1}$ \\ Brahim Bouchrif, ${ }^{2}$ Rajaa Asmai, ${ }^{2}$ Houda \\ En-nassiri, ${ }^{1,2}$ Bouchra Karraouan ${ }^{2}$ \\ ${ }^{1}$ Laboratory of Microbiology, \\ Pharmacology, Biotechnology and \\ Environment, Hassan II University of \\ Casablanca; ${ }^{2}$ Laboratory of \\ Microbiology, Department of Food \\ Hygiene, Products and Environment, \\ Institut Pasteur du Maroc, Casablanca, \\ Morocco
}

\section{Abstract \\ Campylobacteriosis

Campylobacter spp. resistance to antibiotics represents a serious worldwide public health problem thermophilic Campylobacters, in particular, are major causes of gastroenteritis in humans. The aim of this study was to determine the prevalence and antimicrobial resistance of Campylobacter jejuni isolated from chicken droppings, of commercial poultry in the city of Casablanca, Morocco. Between February and September 2017, 140 samples of chicken droppings were collected and analyzed by classical bacteriology methods for isolation and identification according to Moroccan Standard NM ISO/TS 10272-3 (2013), followed by molecular identification (PCR: polymerase chain reaction). Among the 140 samples, 102 (73\%) were positive by Campylobacter spp. tests and 38 (27.14\%) were negative to Campylobacter spp. Among the positive colonies, 41 (40, $2 \%$ ) were $C$. jejuni. Of the $41 C$. jejuni isolates, resistance was detected to tetracycline (100\%), erythromycin (97\%), ampicillin (85\%), ciprofloxacin (77\%), amoxicillin/ clavulanic acid $(61.4 \%)$, and gentamicin $(12.0 \%)$. In conclusion, the data obtained in the current study demonstrate that the majority of $C$. jejuni isolates evaluated were resistant to antimicrobials of the cycline, macrolide, and fluoroquinolone families, and all of the isolates were susceptible to gentamicin. Fluoroquinolone is the drug of choice for treating Campylobacter infections. These results underline the need for prudent use of antibiotics in poultry production to minimize the spread of antibioticresistant Campylobacter spp.

\section{Introduction}

Campylobacter infections are among the leading zoonotic agents causing acute gastroenteritis in developed countries (Parsons et al., 2010; Verma et al., 2014; Campagnolo et al., 2017). Among Campylobacter spp, Campylobacter jejuni is mostly associated with human and other domesticated animal enteritis, followed by Campylobacter coli, Campylobacter upsaliensis, and other species (Moore et al., 2005; Parsons et al., 2010; Campagnolo et al., 2017; Leahy et al., 2017). Campylobacteriosis is the most reported foodborne illness annually in the European Union since 2005. According to the European Food Safety Authority (EFSA), 246,571 cases of verified human campylobacterioses were reported in 2018. In the United States, campylobacteriosis affects a million people a year, and in Canada, there are over 200 thousand cases registered each year (Ravel et al., 2016; Rosenberg et al.,2016). Cases of campylobacteriosis have become common also in Africa, Asia, and the Middle East, particularly in children (Johnson et al., 2017). Poultry is the main reservoir of these pathogens and harbors them without clinical manifestations. Transmission of Campylobacter spp to humans occurs mainly through cross contamination in the kitchen as well as the consumption of contaminated raw/undercooked poultry products or close contact with infected animals (Migura-Garcia et al, 2017; Suzuki et al., 2009). A small proportion of campylobacteriosis cases may be attributed to other animals or environmental sources (Chen et al., 2014). The gastrointestinal manifestations of Campylobacteriosis include cramps, fever, myalgia, weight loss, and acute watery or bloody diarrhea; however, the infection may result in severe extra-intestinal sequelae, especially acute neurological symptoms such as Guillain-Barre syndrome and Miller Fisher syndrome, due to a cross-reactivity between the bacterial lipooligosaccharides and nervous system gangliosides (Ma. SM, 2011). Antibiotic treatment is suggested for patients with severe campylobacteriosis (Kaakoush et al., 2015). There are several common antimicrobial agents for campylobacteriosis therapy: erythromycin, ciprofloxacin, tetracycline, and doxycycline (Wang et al., 2013). But overconsumption, misuse and use of antibiotics by the veterinary industry, to fatten animals and promote their growth, contributes to increased resistance to antibiotics. In Morocco, we are in a therapeutic dead end. In fact, in more than a decade, the consumption of antibiotics has gone from 134.5 million doses to almost
Correspondence: Khadija Es-soucratti, Laboratory of Microbiology, department of food hygiene, products and environment, Institut Pasteur du Maroc, 1 place Louis Pasteur 20360 Casablanca, Morocco.

Tel.: +212643227145

E-mail: khadijaessoucratti@gmail.com

Key words: Campylobacter spp, Chicken droppings, Market, Morocco, Antimicrobial resistance, Molecular identification (PCR).

Acknowledgments: The auhtors thank Pr. Francis Mégraud for her help with correcting the manuscript. We also thank the late Dr. Saber for her permission the samples collection in chickens sold in large markets Casablanca-Settat, Morocco.

Contributions: The authors contributed equally.

Conflict of interests: The authors declare no potential conflict of interests.

Funding: This work was supported by internal funding of the Institut Pasteur de Casablanca and Centre National de Reference des Campylobacters et Helicobacter (CNRCH) en France by the PCR products (primer).

Availability of data and materials: The data that support the findings of this study are available from the corresponding author upon reasonable request.

Ethics approval and consent to participate: This research was conducted in accordance with all relevant guidelines and procedures.

Consent for publication: The manuscript does not contain any individual person's data in any form.

Received for publication: 18 November 2019 Revision received: 20 January 2020.

Accepted for publication: 4 February 2020.

This work is licensed under a Creative Commons Attribution-NonCommercial 4.0 International License (CC BY-NC 4.0).

CCopyright: the Author(s), 2020

Licensee PAGEPress, Italy

Italian Journal of Food Safety 2020; 9:8692

doi:10.4081/ijfs.2020.8692

224 million (2003-2016). The consumption of antibiotics in Morocco is dominated by volume by amoxicillin alone or combined with clavulanic acid (more than 50\%). But Quinolones, followed by combinations of antibiotics (Spiramycin/Metronidazole) and other betalactamines are the most progressive. The consumption of beta lactams (including penicillin derivatives) is largely dominant (61\% in 2016). For example, penicillin resistance increased from $60.3 \%$ in 1999 to over $70 \%$ in 2004 , according to 
data from Information Medicals \& Statistics.

Like many other countries, Morocco has insufficient capacity to cope with antimicrobial resistance. If there is not yet a national multisectoral coordination plan allowing an effective response, Morocco follows many positive approaches revealing its means of combating the problem and notably has several vertical programs endowed with the laboratory capacities necessary to detect antimicrobial resistance and a national protocol to ban the use of antibiotics in animal husbandry from July 2017. despite the fact that broiler producers are required to sign management contracts with veterinary clinics involved in activities related to poultry diseases, in accordance with Moroccan law 49.99 (Law 49-99; 2002) (Rahmatallah et al., 2018). And ONSSA has also taken various measures, including restricting the use of antibiotics in animals. The present study's aim was a comprehensive identification and molecular characterization of $C$. jejuni isolated from chickens, using the classical bacteriology method. Moreover, the strains were identified by molecular identification using the PCR technique and their resistance to several antimicrobials was investigated.

\section{Materials and Methods}

Validation of the method for isolation and identification of Campylobacter in chickens they purchased on a large market of living birds from different farms was undertaken between February and September 2017 during which, 140 samples of chicken droppings were collected from chickens purchased on a large market.

The classical bacteriology method was used for isolation and identification according to the Moroccan Standard NM ISO/TS 10272-3 (2013) is similar to the ISO method for Campylobacter used as reference worldwide just the normalization code. We then carried out the validation of $C$. jejuni by PCR with a positive control $(C$. jejuni ATCC 33560) and negative control (C.coli 33559).

\section{Study area and sample preparation}

This study was conducted in Casablanca, MOROCCO. From February to September 2017, 140 samples of chicken droppings were collected from chickens purchased on a large market from different farms and different flocks in the same site. The sample was taken in a legal and regular manner from different site, twice a month, 10 samples were taken in each sampling precisely on Thursday, which represents the peak of the sale on the market: 5 samples from red chicken (laying chicken) and 5 others from white chicken (broiler chicken) with bird age do not exceed 3 weeks. The droppings are collected by sterile swabs containing $5 \mathrm{~mL}$ of alkaline peptone water (this is the transport medium), then rapidly transported to the laboratory in a cooler.

\section{Isolation and biochemical identification}

Isolation of Campylobacter spp was performed after enrichment as proposed by NM ISO / TS 10272-3 (2013) Food microbiology Horizontal method for the search and enumeration of Campylobacter spp, Part 3: Semi quantitative method. Briefly, 1 $\mathrm{g}$ of dropping contents was transferred to 9 $\mathrm{mL}$ of Preston enrichment broth base (Oxoid CM 0067, Oxoid Ltd., Basingstoke, Hampshire, UK) containing Campylobacter growth factor (Oxoid SR 0232E, Oxoid Ltd.) and 7\% (v/v) defibrinated sheep blood. Incubation was performed in a jar containing a microaerobic atmosphere packet generator $(5 \%$ oxygen, $10 \%$ carbon dioxide, $85 \%$ nitrogen) type CAMPYGen (Oxoid CN0025A, Oxoid Ltd.) during $24 \mathrm{~h}$ at $37{ }^{\circ} \mathrm{C}$. After enrichment, each sample, was directly streaked onto a Campylobacter Selective Agar (Oxoid Ltd.) containing 5\% fresh sterile defibrinated sheep blood and Campylobacter supplement III (Sigma, St. Louis, MO, USA) for primary isolation. Incubation was carried out for $72 \mathrm{~h}$ at $37{ }^{\circ} \mathrm{C}$. One presumptive $C$. jejuni colony from each agar plate was streaked on Colombia blood agar plates and incubated under microaerobic conditions for $24 \mathrm{~h}$ at $37^{\circ} \mathrm{C}$. The isolated colonies were identified by their characteristic morphology on testing of the absence of growth at $25^{\circ} \mathrm{C}$ under aerobic conditions, motility and Gram staining by $100 \times 10$ magnification microscope, open diaphragm and capacitor at maximum with a drop of oil immersion, as well as by oxidase testing. The plates were incubated in an environment of 5\% oxygen, $10 \%$ carbon dioxide, and $85 \%$ nitrogen for $36-48 \mathrm{~h}$ at $37^{\circ} \mathrm{C}$. These tests were followed by confirmation tests using API Campy (bioMérieux, Marcy-l'Etoile, France). All isolates were stored in $25 \%(\mathrm{v} / \mathrm{v})$ glycerolpeptone broth at $-70^{\circ} \mathrm{C}$.

\section{DNA extraction and PCR conditions}

Presumptive Campylobacter spp isolates after purification, one presumptive $C$. jejuni colony from each agar plate was streaked on Colombia blood agar and saved in glycerol-peptone broth at $-70^{\circ} \mathrm{C}$, are revitalized and grown on nutrient agar overnight at $37^{\circ} \mathrm{C}$. After incubation, 3 to 5 colonies of pure strain were harvested and suspended in $100 \mu \mathrm{L}$ in hypotonic water. Cell suspensions were heated at $100^{\circ} \mathrm{C}$ for
$10 \mathrm{~min}$, and then cooled to room temperature. Thereafter, cell suspensions were pelleted by centrifugation at $12,500 \mathrm{rpm} / \mathrm{min}$ for $10 \mathrm{~min}$. The supernatant was collected and transferred to a new tube, then stored in $25 \%(\mathrm{v} / \mathrm{v})$ glycerol-peptone broth at $-70^{\circ} \mathrm{C}$.

The PCR was carried out within a thermal cycler under a final volume of $25 \mu \mathrm{L}$ containing $0.5 \mu \mathrm{L} \mathrm{MgCl}_{2}(25 \mathrm{mM}), 4 \mu \mathrm{L}$ of extracted DNA, $12.5 \mu \mathrm{L}$ RedMixte of Taq DNA polymerase, $0.2 \mu \mathrm{L}$ of each primer $(25 \mathrm{mM})$ for gene amplification (CJ-6027(F) 5'gaatgaaattttagaatgggg3' and CJ-6028(R) 5'gatatgtatgattttatcctgc3'). Amplification conditions for the genes specific to $C$. jejuni were as follows: $95^{\circ} \mathrm{C}$ for $5 \mathrm{~min}$, followed by 30 amplification cycles; denaturation at $95^{\circ} \mathrm{C}$ for $45 \mathrm{sec}$, annealing at $48^{\circ} \mathrm{C}$ for 30 sec, and extension at $72^{\circ} \mathrm{C}$ for $30 \mathrm{sec}$. An additional extension step $\left(5 \mathrm{~min}, 72^{\circ} \mathrm{C}\right)$ was performed. Finally, amplicons were electrophoresed on $2 \%$ agarose gel, colored with ethidium bromide $(0.5 \mu \mathrm{g} / \mathrm{mL})$ and visualized under UV light. The $C$. jejuni PCR product was $358 \mathrm{bp}$ in length (Stonnet et al., 1993). Because we developed a PCR test specific for $C$. jejuni based on the use of oligonucleotide primers that were specifically directed to the synthesis of a $358 \mathrm{bp}$ DNA fragment from the $C$. jejuni genome (Manel et al., 2018). C. jejuni subsp. jejuni ATCC 33560 was used as the reference strain (positif control) and C.coli 33559 (negative control).

\section{Antimicrobial susceptibility testing}

Antimicrobial susceptibility testing was performed by the disk diffusion method using Mueller-Hinton agar (Oxoid Ltd.) supplemented with 5\% defibrinated sheep blood, according to the French Institute of Susceptibility (Manel et al., 2018). Disks impregnated with antibiotics (bioMérieux, Marcy-l'Etoile, France) and their corresponding concentrations were as follows: ciprofloxacin (CIP: $5 \mu \mathrm{g}$ ); erythromycin (E: $30 \mu \mathrm{g})$; gentamicin (GM: $10 \mu \mathrm{g})$; ampicillin (AMP: $30 \mu \mathrm{g}$ ); amoxicillin/clavulanic acid (AMC: $30 \mu \mathrm{g}$ ); tetracycline (TE: $30 \mu \mathrm{g}$ ). Briefly, well-isolated colonies of the same morphological type were selected from an agar culture plate and transferred into 10 $\mathrm{mL}$ of sterile saline buffer $(\mathrm{NaCl} 0.9 \%)$. After homogenization and a 1/10 dilution, 1 $\mathrm{mL}$ of the mixture were flooded onto the surface of a Mueller-Hinton agar (Oxoid Ltd.) containing 5\% defibrinated sheep blood. The inoculum was allowed to dry for $5 \mathrm{~min}$ and antibiotic disks were placed on the plate. After $48 \mathrm{~h}$ of microaerobic incubation at $37^{\circ} \mathrm{C}$ according to the European Committee for Antibiotic Susceptibility Testing (EUCAST), the inhibition zone diameters were measured with calipers. $C$. 
Jejuni ATCC 33560 was used as the reference stress. The isolates were classified as susceptible, intermediate, and resistant according to the EUCAST.

\section{Results}

\section{Prevalence}

Overall, among these 140 analyzed samples, 102 (73\%) Campylobacter spp were identified by a conventional biochemical method according to the Moroccan standard and confirmed by the "API Campy". The colonies appeared smooth and transparent, with a regular border; microscopic observation of colonies in the fresh state revealed bacteria with Campylobacter characteristic motility in the flight of midges and Gram staining (microscopic immersion observation, $X$ 1000) revealed the presence of Gram-negative, S-curved or spiral bacilli and some coccoïdal degenerative forms. Furthermore, these bacteria showed catalase and oxidase-positive activities compatible with the Campylobacter genus. After the biochemical confirmation, we performed a molecular genotypic confirmation by PCR. We developed a PCR test specific for $C$. jejuni based on the use of oligonucleotide primers that were specifically directed to the synthesis of a $358 \mathrm{bp}$ DNA fragment from the $C$. jejuni genome (Manel et al., 2018). In the present study, 102 isolates were analyzed by this PCR, which was carried out blindly. The results are shown in Figure 1. Positive controls were performed by testing DNA from $C$.

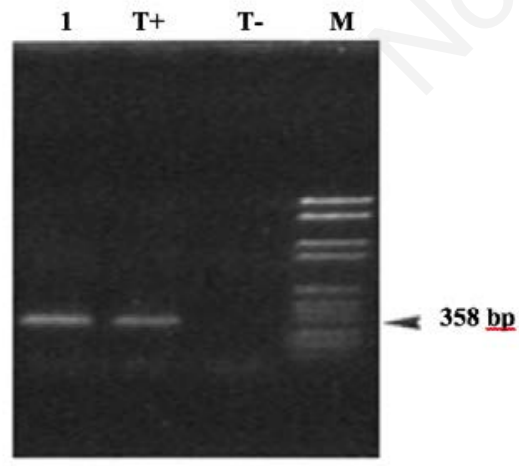

Figure 1. Detection of Campylobacter jeju$n i$ DNA by PCR and gel electrophoresis. The arrow indicates the Campylobacter jejuni-specific 358bp DNA fragment. M: molecular weight amrker VI (Boehringer, Germany); $T+$ : positive control ( $C$. jejuni ATCC33560); T-: negative control; strains (1): C. jejuni. jejuni reference strains. The negative control consisted of all the necessary PCR reagents but without the target DNA which was replaced by $10 \mu \mathrm{l}$ sterile water.

Among the 102 Campylobacter positive isolates analyzed, $41(40,2 \%)$ were $C$. jeju$n i$ and the rest were $C$. coli and others. Moreover, in this study, the prevalence of Campylobacter spp infection was found to be the highest in the summer season (40\%) and the lowest during the cold season (9\%) (Figure 2).

\section{Statistical analysis}

The statistics concerning the prevalence of Campylobacters between the different seasons, using Chi-square tests, shows that the Chi-square value is 20.365 higher than the critical value (Chi-square critical= 7.8417 ) with a significant threshold of 0.05 and degree of freedom of 3 . We therefore conclude that the difference between seasonal prevalence was statistically significant $(\mathrm{P}<0.05)$.

\section{Antimicrobial susceptibility testing of isolated strains}

The results of antimicrobial susceptibility of $C$. jejuni isolates from chicken droppings against the seven tested antimicrobial agents are shown in Table 1.

All isolates $100 \%$ were resistant to tetracycline, and a very high resistance was observed against erythromycin 97\%, ampicillin $85 \%$, and fluoroquinolone (ciprofloxacin) 77\%. To a lesser extent, resistance rate to gentamicin $12.0 \%$. Similar resistance rates were also observed for amoxicillin/clavulanic acid (61.4\%).

\section{Discussion and Conclusions}

Poultry is the main reservoir of Campylobacter spp and poultry consumption represents a major cause of human campylobacteriosis. The presence of such pathogens in poultry is of great concern for

Table 1. Percentages of antibiotic resistance of Campylobacter jejuni (41 isolates) and Campylobacter spp. (102 isolates) isolated from poultry sources in Morocco.

\begin{tabular}{lcc}
\hline Antibiotics & Campylobacter jejuni (n) \% & Campylobacter spp. (n) \% \\
Tetracycline $(30 \mu \mathrm{g})$ & $(41) 100$ & $(93) 91$ \\
Ciprofloxacin $(5 \mu \mathrm{g})$ & $(32) 77$ & $(71) 70$ \\
\hline Ampicillin $(30 \mu \mathrm{g})$ & $(35) 85$ & $(84) 81.9$ \\
Erythromycin $(30 \mu \mathrm{g})$ & $(40) 97$ & $(91) 89$ \\
\hline Amoxicillin + Clavulanic acid $(30 \mu \mathrm{g})$ & $(25) 61.4$ & $(57) 55.5$ \\
Nalidixic acid $(30 \mu \mathrm{g})$ & $(19) 46.2$ & $(41) 40$ \\
\hline Gentamicin $(10 \mu \mathrm{g})$ & $(5) 12$ & (11) 10.3
\end{tabular}

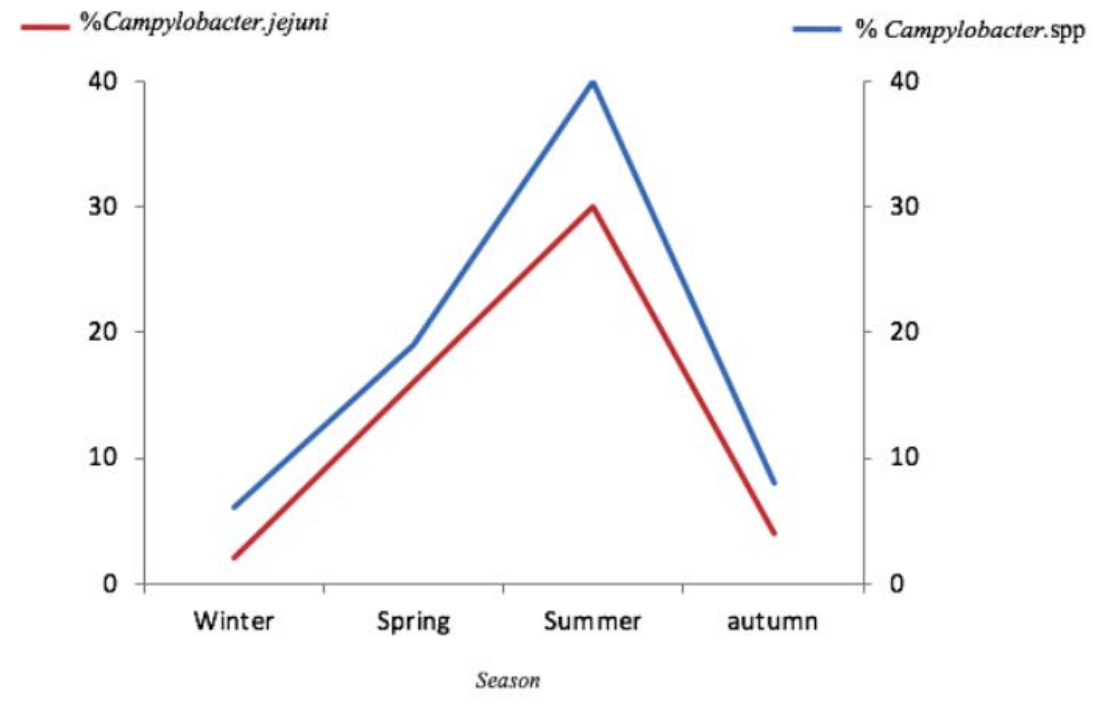

Figure 2. Prevalence of Campylobacter spp and Campylobacter jejuni isolates in poultry according to the different seasons. 
human health, and their control in poultry has a great impact on public health. In Morocco, as in many developing countries, there is limited information regarding Campylobacter status in the conventional poultry sector. Our findings in Casablanca demonstrated that the prevalence of Campylobacter spp was $73 \%$ in chicken dropping samples, including $40.1 \%$ C. jeju$n i$ according to biochemical and molecular identification. This prevalence can be considered as moderate compared to those reported in other studies in different countries. Indeed, studies carried out in Brazil, Costa Rica, and Sri Lanka showed that $100 \%, 80 \%$, and $63.8 \%$ of flocks respectively, were Campylobacter positive (Giacomelli et al., 2014; Kalupahana et al., 2018). The European baseline study on Campylobacter in broilers indicated that the mean EU prevalence was $71.2 \%$, ranging from $2 \%$ in Estonia to a maximum of $100 \%$ in Luxembourg (EFSA, 2010). The prevalence assessed in the present study is higher than the prevalence shown in the European Nordic countries, such as Sweden (13\%), Finland (3.9\%), and Denmark (10.3\%), but lower than the prevalence reported in Spain (88\%), Portugal (82\%), and France (76.1\%). Regarding Campylobacter species distribution, $C$. jejuni was the most common species found (40.1\%) followed by $C$. coli and other species. These results are similar to other investigations reporting $C$. jejuni and $C$. coli as the most frequently isolated species in poultry (Giombelli et al., 2014; Sahin et al., 2015) and their distribution is comparable to our results in Abidjan, $63.75 \%$ in 2010 (Gouali et al., 2010), and in the North of Tunisia a predominance of $C$. jejuni $(68.9 \%)$, followed by C. coli $(31.1 \%)$ in 2018 (Manel et al., 2018).

The prevalence of Campylobacter in poultry in the different areas of Casablanca in Morocco ranged from $70 \%$ to $73 \%$. No significant difference was found related to region distribution, since the samples belong to the same geographic region and have similar climatic conditions. Regarding

Table 2. Prevalence of Campylobacter spp. and Campylobacter jejuni isolates in poultry according to the different seasons.

$\begin{array}{lc}\text { Season } & \text { \% Campylobacter } \\ \text { spp. }\end{array}$

the seasonal distribution, the highest positive rate was found in poultry sampled in the summer $(40 \%)$, while a lower prevalence was found in autumn (8\%) and spring (19\%) (Table 2). Thus, we can conclude that the high prevalence of Campylobacter is related to the season rather than to other factors. In fact, in the spring and summer, the weather in Morocco is warm and humid and the highest heat index (HI) values are noted in the summer. These weather conditions combined with the type of poultry breeding (in the house) seem to be favorable for the survival of Campylobacter in the environment and enhance their spread in flocks (Kalupahana et al., 2018). This positive association is in agreement with data reported by the literature and is supported by the seasonality feature of this disease in humans, with a peak incidence always observed during warm and humid seasons (Nylen et al.,2002).

This seasonality is well illustrated in the study conducted in Switzerland in 2008 (Nylen et al., 2002) where a prevalence of $59.2 \%$ was recorded in the summer season and $46.8 \%$ in the cold season. Another study in the North of Tunisia in 2018 (Manel et al., 2018) shown the difference in the prevalence of Campylobacter according to the season, we find that the highest prevalence of Campylobacter spp infection, was found in the autumn season (52\%) and the lowest during the winter season $(3.5 \%)$. In spring and summer, they obtained the same rate of infection $(11 \%)$. The difference between seasonal prevalence was statistically significant $(\mathrm{P}<0.001)$.

The high prevalence of Campylobacter in poultry may be considered a public health problem since consumers might be exposed to this biological risk. Moreover, Campylobacter strains have developed resistance to several antimicrobial agents over the years, including fluoro quinolones and macrolides, which are the drugs of choice in treatments (di Giannatale et al. ,2014) In this study, our findings revealed the high prevalence $(>77 \%)$. of fluoroquinolone and macrolide resistant Campylobacters in poultry in Morocco. The prevalence of fluoroquinolone-resistant Campylobacters varies greatly between different countries. In Algeria, over 90\% are resistant to quinolones, in particular to ciprofloxacin $(95 \%)$. According to a WHO report (WHO, 2001), no fluoroquinoloneresistant isolate was detected in Norway (Hariharan et al., 2009) and a 9.4\% ciprofloxacin resistance rate was reported in Grenada (Jain et al., 2005). In contrast to the low resistance reported in the above two studies, the rate of ciprofloxacin-resistant Campylobacters was high in India (77.1\%)
(Sonnevend et al., 2006), the United Arab Emirates (85.4\%) (Manel et al., 2018), and South Africa (91\%) (Bsteer et al., 2008). The high fluoroquinolone and macrolide resistance rates of Campylobacter in our study may be attributed to the widespread use of fluoroquinolones and macrolides in poultry production in Morocco. These classes of antibiotics are used for both the prevention and control of poultry diseases. However, the frequency of resistance to ampicillin (85\%), and amoxicillin + clavulanic acid $(61.4 \%)$, tetracycline $(100 \%)$, erythromycin $(97 \%)$, and gentamicin $(12 \%)$ was comparable or lower than in the reports from most of the European countries (Kim et al., 2010; Stonnet et al., 1993), in Italy $27.9 \%$ of the isolates were resistant to gentamicin and $20.9 \%$ were susceptible to both ciprofloxacin and erythromycin. In Tunisia, the following frequencies of resistance were found: erythromycin $(100 \%)$, tetracycline $(100 \%)$, and ciprofloxacin (99.2\%) (Giacomelli et al., 2014; Oporto et al., 2009; Skarp et al., 2016). To the contrary, in countries not permitting the use of fluoroquinolones in poultry production, such as Australia and the European Nordic countries, few resistant Campylobacter isolates were found in chickens and humans: in Australia $15.4 \%$ were resistant to ampicillin, $5.1 \%$ to tetracycline and $13.7 \%$ to ciprofloxacin (Mattheus et al., 2012).

The relatively high percentage of resistance to most antimicrobial agents tested in our study due to the wide use of these agents as growth promoters or in animal treatment. In fact, in Morocco, as in most developing countries (Bsteer et al., 2008), the use of antibiotics for humans and animals is relatively unrestricted. Because Moroccan producers and veterinarians involved in the production of broilers are regular users of antibiotics and it is well known that the use antimicrobials has become a common measure to ensure the economic profitability of broiler producers, In addition, Antibacterial growth activators are still allowed in Morocco and are regularly used by veterinary prescription by animal feed manufacturers. However, studies previous have shown treatment failures associated with reports of increased antibiotic resistance (Rahmatallah et al., 2018). In addition, although the Moroccan authorities apply a surveillance program for certain antimicrobials used in poultry, such as chloramphenicol and gentamicin, since 2001 (ONSSA, 2015). they do not effectively control the use and consumption of antimicrobials in food animals compared to Danish Programme for surveillance of antimicrobial consumption and resistance in bacteria from animals (DANMAP) is a 
German program for monitoring the consumption of antimicrobials and the extent of resistances against antimicrobials in human and veterinary Medicine (GERMAP) in Europe or in the National Animal Health Monitoring System (NAHMS) in ÉtatsUnis. These programs are responsible for collecting, analyzing and of the publication of data on the sale and consumption of antibiotics among farm animals (Merle et al., 2012; FDA, 2014). Today, in the European Union, antibiotics are only used in animals as veterinary medicinal products, subject to veterinary prescription. No more antibiotic molecule is not used in animal production as growth promoters. (Sanders et al., 2011). However, in the États-Unis a large number of antibiotics remains licensed at low dose as growth factors (Thai et al., 2012).

In conclusion, we report the presence of a high contamination of thermophilic Campylobacters in poultry in Morocco and a high resistance of these bacteria to antimicrobials of the fluoroquinolone and macrolide family. These results show the need to strengthen the implementation of specific control procedures to decrease the contamination of poultry meat by Campylobacter and the necessity to reduce the use of antibiotics in the poultry sector. This study also shows the need to establish an efficient system for the control of Campylobacter infection in chickens.

\section{References}

Bsteer LA, Essack SY, 2008. Prevalence of antibiotic resistance in Campylobacter isolates from commercial poultry suppliers in KwaZulu-Natal, South Africa. Antimicrob Chemother 62:1298-300.

Bûttner S, Bruhn S, Danuser J, Overesch G, Schûpbach G, 2008. Baseline study on the prevalence of Campylobacter in broiler flocks and the prevalence of Campylobacter/Salmonella on broiler carcasses. Federal Veterinary Office. Suisse.

Campagnolo ER, Philipp LM, Long JM, Hanshaw NL, 2017. Pet-associated Campylobacteriosis: A persisting public health concern. Zoonoses Public Health 65:304-11.

Chen Z, Jiang X, 2014. Microbiological safety of chicken litter or chicken litterbased organic fertilizers: a review. Agriculture 4:1-29.

di Giannatale E, Di Serafino G, Zilli K, Alessiani A, Sacchini L, Garofolo G, Aprea G, Marotta F, 2014, Characterization of antimicrobial resistance patterns and detection of virulence genes in Campylobacter isolates in Italy. Sensors 14:3308-22.

European Food Safety Authority (EFSA), 2010. The community summary report on trends and sources of zoonoses'. Zoonotic agents and foodborne outbreaks in the European Union (2008). EFSA J 8:1496-906.

Food and Drugs Administration (FDA), 2014. Annual summary report on antimicrobials sold or distributed in 2012 for use in food-producing animals.

Giacomelli M, Salata C, Martini M, Montesissa C, Piccirillo A, 2014. Antimicrobial resistance of Campylobacter jejuni and Campylobacter coli from poultry in Italy. Microb Drug Resist 20:181-8.

Giombelli A, Gloria MBA, 2014. Prevalence of Salmonella and Campylobacter on broiler chickens from farm to slaughter and efficiency of methods to remove visible fecal contamination. J Food Protect 77:1851-9.

Goualie GB, Karou GT, Bakayoko S, Coulibaly KJ, Coulibaly KE, Niamke SL, Dosso Raspa M, 2010. Prevalence of Campylobacter in chickens sold in Abidjan markets: Pilot study conducted in Adjamé commune in 2005. 8:N0S.

Hariharan H, Sharma. S, Chikweto. A, Matthew. V, DeAllie. C, 2009. Antimicrobial drug resistance as determined by the E-test in Campylobacter jejuni, C. coli, and C. lari isolates from the ceca of broiler and layer chickens in Grenada. Comp. Immun. Microbiol. Infect. Dis. 32: 21-28.

Jain D, Sinha S, Prasad KN, Pandey CM, 2005. Campylobacter species and drug resistance in a north Indian rural community. Trans R Soc Trop Med Hyg 99:207-14.

Johnson TJ, Shank JM, Johnson JG, 2017. Current and Potential Treatments for Reducing Campylobacter Colonization in Animal Hosts and Disease in Humans. Front Microbiol 8:487.

Kaakoush NO, Castaño-Rodríguez N, Mitchell HM, Man SM, 2015. Global epidemiology of campylobacter infection. Clin Microbiol Rev 28:687-720.

Kalupahana RS, Mughini-Gras L, Kottawatta SA, Somarathne S, Gamage C, Wagenaar JA, 2018. Weather correlates of Campylobacter prevalence in broilers at slaughter under tropical conditions in Sri Lanka. Epidemiol Infect 146:972-9.

Kim HJ, Kim JH, Kim YI, 2010. Prevalence and characterization of Campylobacter spp. isolated from domestic and imported poultry meat in Korea, 2004-2008. Foodborne Pathog Dis 7:1203-9.

Leahy AM, Cummings KJ, Rodriguez-
Rivera LD, Hamer SA, Lawhon SD, 2017. Faecal Campylobacter shedding among dogs in animal shelters across Texas. Zoonoses Public Health 64:6237.

Ma SM, 2011. The clinical importance of emerging Campylobacter species. Nat Rev Gastroenterol Hepatol 8:669-85.

Manel G, 2018 Prevalence and Antibiotic Resistance Patterns of Campylobacter spp. Isolated from Broiler Chickens in the North of Tunisia. Biomed Res Int 2018:7943786.

Manfreda G, Parisi A, De Cesare A, Mion D, Piva S, Zanoni RG, 2016. Typing of Campylobacter jejuni Isolated from Turkey by genotypic methods, antimicrobial susceptibility, and virulence gene patterns: a retrospective study. Foodborne Pathog Dis 13:93-100.

Mattheus W, Botteldoorn N, Heylen K, Pochet B, Dierick K, 2012. Trend analysis of antimicrobial resistance in Campylobacter jejuni and Campylobacter coli isolated from belgian pork and poultry meat products using surveillance data of 2004-2009. Foodborn Pathog Dis 9:465- 72.

Merle R, Hajek P, Käsbohrer A, HeggerGravenhorst C, Mollenhauer Y, Robanus M, 2012. Monitoring of antibiotic consumption in livestock: a German feasibility study. Prev Vet Med 104:34-43.

Moore JE, Corcoran D, Dooby SG, Lucey B, Matsuda M, McDowell A, Megraud F, Millar BO, Mahony R, Riordan L, O'Rourke M, Rao J, Rooney P, Sails A, Whyte P. 2005. Campylobacter. Vet Res 36:351-82.

Migura-Garcia L, Ramos R, 2017. Antimicrobial resistance of salmonella serovars and Campylobacter spp. isolated from an opportunistic gull species, yellow-legged gull (Larusmichahellis). J Wildlife Dis 53:148-52.

Norstro M, Johnsen G, Hofshagen H, Tharaldsen H, Kruse H, 2007. Antimicrobial resistance in Campylobacter jejuni from broilers and broiler house environments in Norway. J Food Prot 70:736-8.

Nylen G, Dunstan F, Palmer S, 2002. The seasonal distribution of campylobacter infection in nine European countries and New Zealand. Epidemiol Infect 128:383-90.

ONSSA. Requirements for poultry production. 10 March 2015.

Oporto B, Juste R, Hurtado A, 2009. Phenotypic and genotypic antimicrobial resistance profiles of Campylobacter jejuni isolated from cattle, sheep, and free-range poultry faeces. Int $\mathrm{J}$ 
Microbiol 2009:456573.

Parsons BN, Porter CJ, Ryvar R, Stavisky J, Williams NJ, Pinchbeck GL, Birtles RJ, Christley RM, German AJ, Radford AD, Hart CA, Gaskell RM, Dawson S, 2010. Prevalence of Campylobacter spp. in a cross-sectional study of dogs attending veterinary practices in the UK and risk indicators associated with shedding. Vet J 184:66-70.

Rahmatallah N, El Rhaffouli H, Lahlou Amine I, Sekhsokh Y, Fassi Fihri O, El Houadfi M, 2018. Consumption of antibacterial molecules in broiler production in Morocco. Vet Med Sci 4:8090.

Ravel A, Pintar K, Nesbitt A, Pollari F, 2016. Non food-related risk factors of campylobacteriosis in Canada: A matched case-control study. BMC Public Health 16:1016.

Rosenberg Goldstein RE, Cruz-Cano R, Jiang C, Palmer A, Blythe D, Ryan P, Hogan B, White B, Dunn JR, Libby T, 2016. Association between community socioeconomic factors, animal feeding operations, and campylobacteriosis incidence rates: Foodborne Diseases
Active Surveillance Network (FoodNet), 2004-2010. BMC Infect Dis 16:354.

Sahin O, Kassem II, Shen Z, Lin J, Rajashekara G, Zhang Q, 2015. Campylobacter in poultry: ecology and potential interventions. Avian Dis 59:185-200.

Sanders P, Bousquet-Mélou A, Chauvin C, Toutain PL, 2011. Utilisation des antibiotiques en élevage et enjeux de santé publique. INRA Prod Anim 24:199204.

Skarp CPA, Anninen MLH, Rautelin HIK, 2016. Campylobacteriosis: The role of poultry meat. Clin Microbiol Infect 22:103-9.

Sonnevend A, Rotimi VO, Kolodziejek J, Usmani A, Nowotny N, Pal T, 2006. High level of ciprofloxacin resistance and its molecular background among Campylobacter jejuni strains isolated in the United Arab Emirates. J Med Microbiol 55:1533-8.

Stonnet V, Guesdon JL, 1993. Campylobacter jejuni: specific oligonucleotides and DNA probes for use in polymerase chain reaction-based diag- nosis. FEMS Immunol Med Microbiol 7:337- 44.

Suzuki H, Yamamoto S, 2009. Campylobacter contamination in retail poultry meats and by-products in the world: a literature survey. J Vet Med Sci 71:255-61.

Thai TH, Hirai T, Lan NT, Yamaguchi R, 2012. Antibiotic resistance profiles of Salmonella serovars isolated from retail pork and chicken meat in North Vietnam. Int J Food Microbiol 156:14751.

Verma AK, Kumar A, Singh SK, Rahal A, Ahmed I, Singh D, Singh AP, Singh L, 2014. Prevalence and resistance to antimicrobial agents of Campylobacter spp. isolated from dogs in India. J Biolog Sci 14:142-8.

Wang G, Sjolund-Karlsson B, McDermott M, 2013. Antimicrobial resistance in campylobacter: susceptibility testing methods and resistance trends. J Microbiol Methods 95:57-67.

WHO, 2001. WHO 2001 global strategy for containment of antimicrobial resistance. 